\title{
Phosphorylation of Brain Sodium Channels in the I-II Linker Modulates Channel Function in Xenopus Oocytes
}

\author{
Raymond D. Smith and Alan L. Goldin \\ Department of Microbiology and Molecular Genetics, University of California, Irvine, California 92717-4025
}

Voltage-gated sodium channels, which initiate action potentials in mammalian brain neurons, are modulated functionally by CAMP-dependent protein kinase $A(P K A)$, resulting in reduced sodium current amplitude. Comparing brain and muscle sodium channels, we show that only the brain channel is modulated by PKA. The brain sodium channel I-II linker is both necessary and sufficient for PKA modulation, as shown by exchanging the $1-\|$ linker regions of the two channels. PKA consensus sites in the brain channel I-II linker were eliminated by deletion and site-specific mutagenesis. The mutant chan- nels demonstrated decreased levels of phosphorylation when metabolically labeled in oocytes with $\left[\gamma_{-}{ }^{32} \mathrm{P}\right]-\mathrm{ATP}$, and they did not respond with a reduction in current magnitude after PKA induction. Modulation of the brain channel by PKA phosphorylation was mimicked by adding fixed negative charges at the PKA consensus sites, suggesting that the decrease in current was a direct result of the negative charge at one or more of the PKA sites in the I-II linker.

Key words: sodium channels; phosphorylation; protein kinase A; ion channel modulation; cAMP; mutagenesis
Voltage-gated sodium channels mediate the initial rising phase of membrane depolarization during action potentials in electrically excitable cells. For this reason, modulation of neuronal sodium channel activity can have a profound effect on the transmission of action potentials in nerve cells. One means by which sodium channel activity can be modulated is by phosphorylation. Brain sodium channels have been shown to be modulated functionally by protein kinase $\mathrm{C}$ (PKC) and protein kinase A (PKA). Phosphorylation by $\mathrm{PKC}$ at a serine residue (S1506) in the linker region between domains III and IV reduces sodium current magnitude (Dascal and Lotan, 1991; Numann et al., 1991; Schreibmayer et al., 1991) and slows the rate of fast inactivation (Numann et al., 1991). The predominant effect of PKA phosphorylation is to diminish sodium current amplitudes (Gershon et al., 1992; Li et al., 1992) resulting from a reduction in the open probability of the channel (Li et al., 1992). Decreased current amplitudes resulting from PKA phosphorylation are observed only when the PKC site at $\mathrm{S} 1506$ is phosphorylated, demonstrating a convergence between modulation by PKC and PKA (Li et al., 1993). In some circumstances, PKA phosphorylation also can increase sodium current amplitudes (Smith and Goldin, 1992). The increase was observed when PKA activity was maintained at an elevated initial level, and then stimulated to very high levels, in Xenopus oocytes (Smith and Goldin, 1992).

The rat brain type IIA sodium channel is comprised of a main pore-forming $\alpha$-subunit and two accessory subunits, $\beta 1$ and $\beta 2$. It is well established that the rat brain sodium channel $\alpha$ subunit is a substrate for phosphorylation by PKA (Costa et al., 1982; Rossie et al., 1987; Rossie and Catterall, 1989). There are five sites

Received Sept. 19, 1995; revised Dec. 18, 1995; accepted Dec. 27, 1995.

This work was supported by grants to A.L.G. from National Institutes of Health (NS26729), the National Multiple Sclerosis Society, and the Muscular Dystrophy Association. A.L.G. is an Established Investigator of the American Heart Association. We thank Dr. Gail Mandel for the rat skeletal muscle sodium channel clone; Dr. Mike White for the $\beta$-adrenergic receptor clone; and Dr. Kris Kontis, Ted Shih, and Marianne Depp for helpful discussions during the course of this work.

Correspondence should be addressed to Alan L. Goldin at the above address.

Copyright 101996 Society for Neuroscience $0270-6474 / 96 / 161965-10 \$ 05.00 / 0$ located in the linker region between domains I and II of the rat brain type IIA sodium channel that match PKA consensus sites described by RRXS/T and KRXXS/T (Kemp and Pearson, 1990). It has been shown biochemically that PKA phosphorylation of the $\alpha$-subunit of the channel in vivo is restricted to four of those sites (Murphy et al., 1993). In addition, it has been shown recently that the same four sites are dephosphorylated in the brain by phosphatase 2A and calcineurin (Chen et al., 1995). Therefore, the level of phosphorylation at those sites is likely to be tightly regulated. However, it has not been demonstrated that the functional effects of PKA activation result from direct phosphorylation of the channel at the PKA sites in the I-II linker.

The muscle SkM1 sodium channel I-II linker is substantially shorter than the brain IIA linker, and it completely lacks PKA consensus sites. We therefore compared the brain and muscle sodium channels under conditions of PKA induction to determine whether the brain channel I-II linker is involved in PKA modulation. In the conditions used in this study, sodium currents through the brain channel were decreased by PKA induction, but currents through the muscle channel were unaffected. By constructing chimeric channels in which the I-II linker was exchanged between the brain and muscle channels, we demonstrated that the brain I-II linker is both necessary and sufficient for the decrease in current size. Removal of the PKA sites by deletion or replacement of the serines with alanines eliminated the current decrease resulting from PKA stimulation. Finally, replacement of the serine residues with aspartates resulted in a channel with constitutively decreased current amplitudes.

\section{MATERIALS AND METHODS}

Site-directed mutagenesis. The plasmid pVA2580 contains the rat brain IIA (RIIA) sodium channel coding region downstream from a T7 RNA polymerase promoter (Auld et al., 1990). The I-II linker region of RIIA, as defined by the unique Tth $111 \mathrm{I}$ and $S p h \mathrm{I}$ restriction sites in pVA2580, was subcloned into $\mathrm{mp} 18 \mathrm{~A}$, a version of $\mathrm{mp} 18$ with a polylinker region that was modified to contain unique restriction sites in the RIIA coding region. The plasmid $\mu 1$ contains the rat skeletal muscle SkM1 coding region downstream from a $T 7$ promoter (Trimmer et al., 1989), and was generously provided by Dr. Gail Mandel (SUNY Stony Brook). The I-II 
linker region of SkM1 was subcloned into mp18A using the restriction sites BstEII and SphI. M13 single-strand mutagenesis was used to create mutations as described previously (Kunkel, 1985). Uracil-containing, single-stranded DNA was isolated from phage grown in the dut $u n g^{-} E$. coli strain RZ1032 in YT media supplemented with $250 \mu \mathrm{g} / \mathrm{ml}$ uridine. Oligonucleotide primers were kinased with T4 polynucleotide kinase and annealed to templates at a 10:1 molar ratio. The primers were extended with T4 DNA polymerase (2.5 units) in the presence of T4 DNA ligase (6 Weiss units) in a $100 \mu \mathrm{l}$ reaction containing (in mM): Tris- $\mathrm{HCl} 20, \mathrm{pH} 7.5$, $\mathrm{MgCl}_{2}$ 10, dNTPs 0.5, ATP 1, and DTT 2, pH 7.5. Reaction mixtures were incubated first on ice for $5 \mathrm{~min}$, then at room temperature for $5 \mathrm{~min}$, and finally at $37^{\circ} \mathrm{C}$ for $2 \mathrm{hr}$. XL-1 bacteria were transformed with the heteroduplex DNA by electroporation and plated with XL-1 lawn cells. Individual plaques were picked and plaque purified before growing up phage to isolate single-stranded DNA, which was used to screen for mutations by dideoxynucleotide sequencing. Double-stranded RF DNA was isolated and digested with appropriate restriction enzymes to ligate the sodium channel region containing the mutations back into the plasmid containing the full-length coding region.

To construct the $\triangle$ PKA mutant, the region of pVA2580 from AatII to $B g l I I$ was subcloned into mp18A. M13 single-strand mutagenesis was used to loop out the coding region for 139 amino acids, which contains the PKA sites. The PKACOMP-A mutant was constructed by mutating each of the serines at amino acid positions 554, 555, 573, 610, 623, 686, 687 , and 688 to alanine. The five individual mutations were combined in the subclone Tth111I SphI in pGEMI8A by cutting and ligating DNA fragments using the restriction sites Tth 111 I, FokI, TaqI, RsaI, XmaI, and SphI. The PKACOMP-D mutant was constructed using a simplificd strategy in which all five of the PKA sites werc converted together with one T4 DNA polymerase second-strand synthesis reaction using five mutagenic oligonucleotides. Three of five isolates contained all of the serine to aspartate mutations. The region containing all of the mutations was transferred back into the full-length sodium channel using the Aatll and $B g I I I$ restriction sites. The FLAG epitope(DYKDDDDK) (Hopp et al., 1988) was incorporated into the amino terminus of the sodium channel using M13 loop-in insertion mutagenesis.

The various mutations were constructed using the following oligonucleotides:

DPKA: CAAGTCCATAGAGACGTGGTACTCGTAGGTCAATCTACTTCC

S554A/D-S555A/D: GACTGGTGCGGA(G/T)CG(G/T)CAAATCTCTTCTC

S573A/D: AGGCTTGCTCTA(C/T)CGTTGCGTCTT

S610A/D: GGTACAAATAGA(G/T)CGTCTCTTCTG

S623A/D: CCTGGCTGACATTG(G/T)CAGGACGCCTTTCTC S686A/ D-S687A/D-S688A/D: GAGACGTGGTAA(G/T)CA(G/T)CG(G/T)CTCTCCTCTTCCT

FLAG insertion:

\section{GACCGTGCTTTATCGTCATCGTCTTTATAGTCCATTCTT-} TGTCGACG

Construction of chimeric sodium channels, 'To generate the BMB chimera, the region of pVA2580 from Tth111I to SphI was subcloned into a modificd version of mp $18 \mathrm{~A}$. Silent mutations were created at amino acids V424/A425 to produce an $\mathrm{NruI}$ restriction site and at amino acid V761 to create a SalI restriction site. The SkM1 I-II linker was amplified using the polymerase chain reaction, incorporating $N r u I$ and $S a l l$ sites at the appropriate ends, and inserted into the brain sequence between the $N r u \mathbf{I}$ and SalI sites. The region from Tth111I to SphI, containing BMB sequence, was transferred back into pVA2580. The MBM chimera was created by the inverse strategy. BstEII and $S p h I$ were used to subclone SkM1 sequence into mp18A, and silent mutations were constructed at positions V440/A441 and V574 to insert NruI and SalI sites at the ends of the I-II linker. The polymerase chain reaction was used to add NruI and SalI sites onto the ends of the RIIA I-II linker, which was inserted between the NruI and SalI sites in the SkM1 I-II linker subclone. The chimeric I-II linker subclone was transferred into the plasmid containing the full-length SkM1 using BstEII and $S p h \mathbf{I}$.

The silent mutations were constructed using the following oligonucleotides:

V424/A425 (NruI sile in RIIA): CGTATGGCCATCGCGACCACAGCCA

V761 (Sall site in RIIA): TGGCCAGGTCGACAAATGGAT

V440/A441 (NruI site in SkM1): GGCCGTGGTCGCGATGGCGTACG

V574 (Sall site in SkM1): CCCCTTTGTCGACCTGGGTATC
The primers for the polymerase chain reaction to add restriction sites were as follows:

NruI in RIIA: GCGCTCGCGATGGCCTACGAGGAAC

SalI in RIIA: GCGCGTCGACAAATGGATCCATCAC

Nril in SkM1: GCGCGCGTCGAGAAAGGGGTCCATG

Sall in SkM1: GCGCGCTCGCGATGGCGTACGCTG

Transcription of RNA and expression in Xenopus oocytes. RNA transcripts were synthesized from linearized DNA templates using a T7 RNA polymerase transcription kit (Ambion, Austin, TX). BspD1 or NotI was used to linearize plasmid DNA for pVA2580, $\triangle$ PKA, PKACOMP-A, PKACOMP-D, SkM1, and the BMB and MBM chimeras. Bam HI was used to linearize the pBART plasmid containing the $\beta$-adrenergic receptor $(\beta-\mathrm{AR})$ coding region downstream from an SP6 polymerase promoter (White and Reisine, 1990), which was generously provided by Dr. Mike White (Medical College of Pennsylvania). To quantify the amount of RNA synthesized, $\left[\alpha-{ }^{32} P\right] C T P$ was added to RNA synthesis reactions to determine the fraction of total $\mathrm{cpm}$ incorporated. The yield of RNA was calculated by assuming cquivalent incorporation of all four ribonucleotides. Stage V oocytes were removed from adult female Xenoptes laevis frogs and prepared as described previously (Goldin, 1991) and incubated in ND-96 media containing (in $\mathrm{mm}$ ): $\mathrm{NaCl} 96, \mathrm{KCl} 2, \mathrm{CaCl}_{2} 1.8, \mathrm{MgCl}_{2} 1$, HEPES 5, pH 7.5, supplemented with $0.1 \mathrm{mg} / \mathrm{ml}$ gentamicin, $0.55 \mathrm{mg} / \mathrm{ml}$ pyruvate, and $0.5 \mathrm{~mm}$ theophylline. Sodium channel RNA was injected at $-100 \mathrm{pg} /$ oocytc, and $\beta$-AR RNA was injected at $50 \mathrm{pg} / 0$ ocyte. After a 40 hr incubation at $20^{\circ} \mathrm{C}$ in ND96, sodium currents were recorded using a two-electrode voltage clamp at room temperature, as described previously (Patton and Goldin, 1991). The bath recording solution consisted of ND-96, and PKA was induced by perfusing oocytes with $4 \mu \mathrm{M}$ isoproterenol in bath solution for $10 \mathrm{~min}$. Stock solutions of isoproterenol (Sigma, St. Louis, MO) were made at a concentration of $100 \mathrm{~mm}$ in water and stored at $-20^{\circ} \mathrm{C}$. The rate of perfusion with bath solution was adjusted carefully to $0.1 \mathrm{drop} / \mathrm{sec}$ to minimize fluctuations in current amplitude resulting from changes in flow rate.

Isolation of sodium channel protein from oocytes. Oocytes were injected in batches of 200 with $50 \mathrm{ng} /$ oocyte of RNA encoding the wild-type or mutant sodium channel containing the FLAG epitope (DYKDDDDK) at the amino terminus. Insertion of $\Gamma L A G$ did not alter the functional properties of the channel. Half of the oocytes were coinjected with 500 $\mathrm{nCi}$ of $\left[{ }^{35} \mathrm{~S}\right]$ methionine (Dupont NEN, Boston, MA) at the time of RNA injection to determine the total amount of sodium channel protein synthesized, and the other half were injected a second time with $500 \mathrm{nCi}$ $\left[\gamma_{-}{ }^{32} \mathrm{P}\right]$ ATP (Dupont NEN) $20 \mathrm{hr}$ before isolation of sodium channel protein from the oocytes to determine the amount of phosphorylated sodium channel protein. Sodium channel protein was purified from oocytes by a modification of the method used by Santacruz-Toloza et al. (1994) for the purification of the Shaker $\mathrm{K}^{+}$channel protcin. Oocytes were solubilized by douncing in $0.5 \mathrm{ml}$ of solution containing $10 \%$ sucrose and (in $\mathrm{mM}$ ) $\mathrm{NaCl} 150, \mathrm{KCl} 5, \mathrm{Mg}$ acetate 10, HEPES 20, $\mathrm{pH} 7.5$, including protease inhibitors $(40 \mu \mathrm{g} / \mathrm{ml}$ bestatin, $50 \mu \mathrm{g} / \mathrm{ml}$ antipain, 0.5 $\mu \mathrm{g} / \mathrm{ml}$ leupeptin, $0.7 \mu \mathrm{g} / \mathrm{ml}$ aprotinin, $25 \mu \mathrm{g} / \mathrm{ml}$ 4-(amidinophenyl) methanesulfonyl fluoride, $0.1 \mathrm{~mm}$ EDTA, $0.5 \mathrm{~mm}$ PMSF, and $0.5 \mathrm{~mm}$ DTT), and phosphatase inhibitors ( $50 \mathrm{~mm} \mathrm{KF}$ and $5 \mathrm{~mm} \beta$-glycerophosphate). The homogenized samples were overlaid on a sucrose step-gradient $(10 \% / 20 \% / 50 \%)$ in the same buffer and centrifuged at $170,000 \times g$ for 30 min at $4^{\circ} \mathrm{C}$ in a Beckman SW41 rotor. The oocyte membrane fraction was isolated from the $20-50 \%$ sucrose interface using a Pasteur pipette. The membrane fraction was washed by adding $8 \mathrm{ml}$ of water, followed by centrifuging at $100,000 \times g$ for $10 \mathrm{~min}$ at $4^{\circ} \mathrm{C}$. The membrane-bound proteins in the pellet were solubilized in $75 \mathrm{~mm} \mathrm{KCl}, 75 \mathrm{~mm} \mathrm{NaCl}, 50 \mathrm{~mm}$ sodium phosphate, $\mathrm{pH} 7.2,2 \mathrm{mg} / \mathrm{ml}$ crude soybean lipids (Avanti Polar Lipids, Alabaster, AL), $1 \%$ Triton X-100, $1.8 \mathrm{mM} \mathrm{CaCl}_{2}$, in addition to the protease and phosphatase inhibitors listed previously. Insoluble material was eliminated by centrifuging at $100,000 \times g$ for $30 \mathrm{~min}$ at $4^{\circ} \mathrm{C}$. Sodium channel protein in the supernatant was immunoprecipitated from the membrane fraction by adding $2 \mu \mathrm{l}$ of $1.55 \mathrm{mg} / \mathrm{ml} \mathrm{M} 2$ anti-FLAG antibody (VWR, Cerritos, CA) and incubating for $4 \mathrm{hr}$ at $4^{\circ} \mathrm{C}$, followed by addition of $150 \mu \mathrm{l}$ of hydrated, $\mathrm{pH}$-neutralized, protein-A sepharose (Pharmacia LKB, Alameda, CA) and incubating for another $2 \mathrm{hr}$ at $4^{\circ} \mathrm{C}$. Immune complexes were released from the protein-A Sepharose beads by boiling for $3 \mathrm{~min}$ in $50 \mu \mathrm{l}$ of SDS PAGE sample loading buffer. The proteins were analyzed on a $7.5 \%$ SDS polyacrylamide gel with a $3 \%$ stacking gel. The gel was dried and analyzed by autoradiography ( $7 \mathrm{~d}$ exposure), and the ${ }^{35} \mathrm{~S}$ and ${ }^{32} \mathrm{P}$ signals in the bands corresponding to the sodium channel proteins were quantified by scanning densitometry. 
A

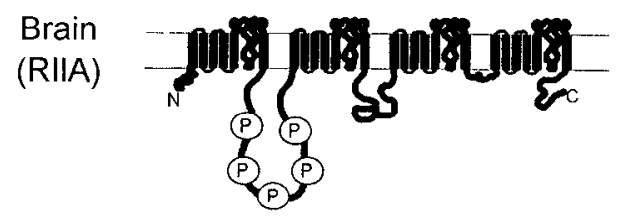

$\underset{\text { Chimera }}{\text { BMB }} \underset{\mathrm{N}}{\mathrm{S}}$
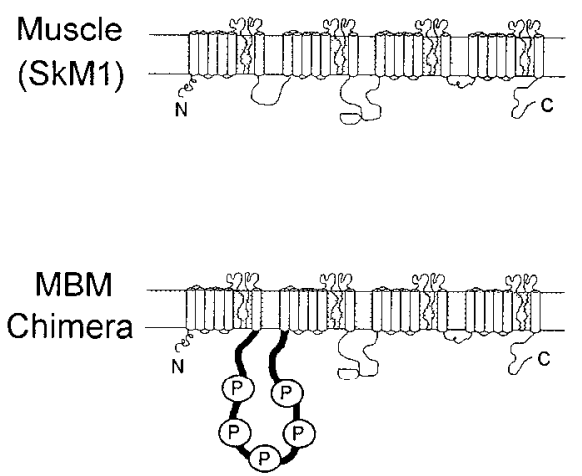

B

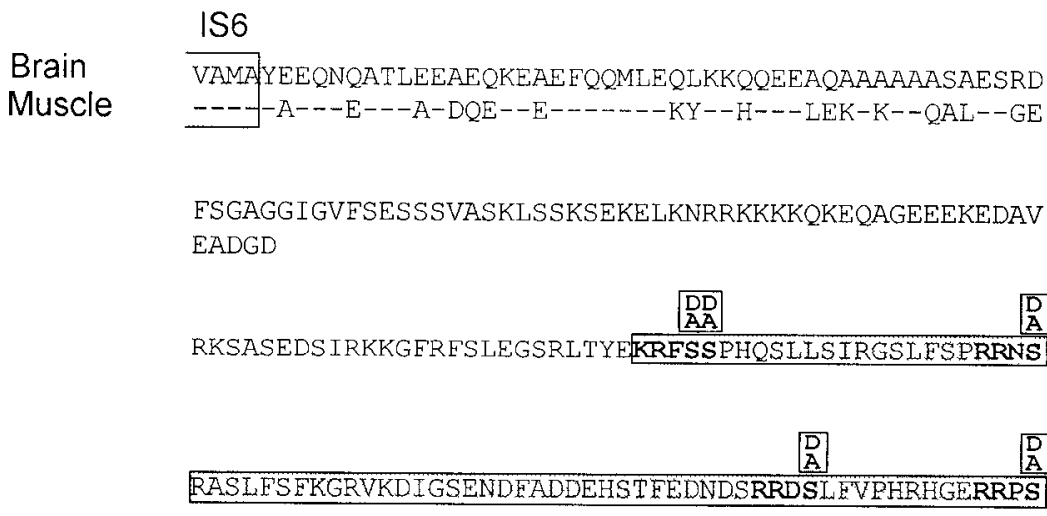

WVSQASRASRGIPTEPMNGKMHSAVDCNGVVSZVGGPSALTSPVGQLEPE - THN$-\cdots-$ SLDAS -

\section{DDDD}

GTTTETEIRKRRSSSYHVSMDLLEDPSRQRAMSMAS I LTNTMEELEESRQ -KGPPRPSC-AD-AISDA------AH-

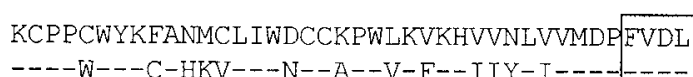

IIS1
(473)

(489)

(523)

(494)

(573)

(623)

(494)

(673)

(509)

(763)

(576)

Figure 1. Diagram of chimcric and PKA site mutant sodium channels. $A$, Diagram of the rat brain IIA and skeletal muscle SkM1 sodium channels, emphasizing the presence of the five consensus PKA phosphorylation sites (RRXS/T and KRXXS/T). which are indicated by a circled $P$ on the I-II linker. The BMB chimera contains the skeletal muscle channel I-II linker in a brain channel background, and the MBM channel contains the brain channel I-II linker in a skeletal muscle channel background. $B$, Sequence alignment of the brain and muscle sodium channel I-II linker region amino acid sequences. $\mathrm{Pu}$ tative transmembrane regions $I S 6$ and IISI are shown at the cnds of the linker. The sequence for the brain channel is shown on the top, with the sequence for the muscle channel shown below. Dashes in the muscle sequence indicate that the residue at that position is identical to that shown for the brain channel sequence. The five consensus PKA sites are shown in bold. The central region of the brain channel linker that was deleted to construct $\triangle$ PKA is indicated by the shaded sequence in the boxes. The amino acid substitutions that were made to construct the two composite site mutations, PKACOMP-A, with $S$ replaced by $A$, and PKACOMP-D, with $S$ replaced by $D$, are shown above the sequence. The numbers in parentheses indicate the amino acid position for the brain and muscle channcls.

Data analysis. Currents were measured and analyzed using pClamp 6.0.2 software (Axon Instruments, Foster City, CA). Conductance values were calculated using the formula $G=I /\left(V-V_{r}\right)$, where $G$ is conductance, $I$ is current amplitude, $V$ is the depolarized membrane potential, and $V_{r}$ is the reversal potential for sodium. Reversal potentials were estimated individually for each data set by fitting the I-V data as described previously (Kontis and Goldin, 1993). Conductance values were fit with a two-state Boltzmann equation, $G=1 /(1+$ $\left.\exp \left[-0.03937 \times z \times\left(V-V_{1 / 2}\right)\right]\right)$, with $z$ equal to the apparent gating charge, $V$ equal to the command potential, and $V_{1 / 2}$ equal to the voltage required for half-maximal activation. The voltage dependence of fast inactivation data were fit with a two-state Boltzmann equation, $I$ $1 /\left(1+\exp \left[\left(V-V_{1 / 2}\right) / a\right]\right)$, with $I$ equal to the current amplitude measured during the test depolarization, $V$ equal to the inactivating depolarization potential, a equal to the slope factor, and $V_{1 / 2}$ equal to the voltage depolarization required for half-maximal inactivation. Sequence comparison of the RIIA and SkM1 I-II linker sequences were made using Clustal $\mathrm{V}$ multiple sequence alignment software. Gel autoradiographs were scanned with a Hewlett Packard Scanjet IIcx/T with a transparency adapter, and band densities were quantified using SigmaScan software (Jandel, San Rafael, CA). Gel images presented in Figures 4 and 6 (see below) were made by converting the labeled, but otherwise unmodified, scanned images to prints.

\section{RESULTS}

\section{The brain sodium channel I-II linker is a critical determinant for modulation by PKA}

The rat brain IIA and muscle SkM1 sodium channels differ strikingly within the cytoplasmic linker between domains I and II. The brain isoform has five PKA sites present in the I-II linker, whereas the muscle channel completely lacks PKA sites in that region (Fig. $1 A, B$ ). We therefore compared the effect of PKA induction on these two channels in Xenopus oocytes to determine whether they are modulated differently by PKA. Oocytes were coinjected with RNA encoding the sodium channel and with RNA 


\section{A}

Figure 2. The brain sodium channel I-II linker is a critical determinant for modulation of the channel. $A$, Normalized peak current amplitudes are shown for representative oocytes injected with RNA encoding the $\beta$-AR and either the brain IIA channel (RILA; circles) or the skeletal muscle channel (SkM1; squares). Currents were elicited by step depolarizations from a holding potential of -100 to $-10 \mathrm{mV}$ at $1 \mathrm{~min}$ intervals, and the peak current amplitudes were normalized to the peak current amplitude during the first depolarization. PKA was induced by perfusion with isoproterenol $(+I$ so $)$ for $10 \mathrm{~min}$ during the time indicated by the bar. $B$, Normalized peak current amplitudes are shown for representative oocytes injected with RNA encoding the $\beta$-AR and either the skeletal muscle channel (SkMI; squares) or the $B M B$ chimcra (inverted triangles). The experimental protocol was the same as described for $A$. $C$, Normalized peak current amplitudes are shown for representative oocytes injected with RNA encoding the $\beta$-AR and either the brain IIA channel (RIIA; circles) or the $M B M$ chimera (triangles). The experimental protocol was the same as described for $A$. $D$, The percent of current decrease 15 min after PKA induction (indicated by the arrowheads on the time axis in $A-C$ ) is shown for the brain, muscle, and chimeric sodium channels. The values shown are the averages for three oocytes $(R I I A)$, four oocytes $(M B M)$, fivc oocytes $(S k M I)$, and four oocytes $(B M B)$, and the error bars indicate the sample SDs. Sodium currents expressed for SkM1 and MBM did not reach steady-state levels, but increased linearly by $20-40 \%$ over the $50 \mathrm{~min}$ interval. In those cases, the peak currents were adjusted by subtracting a linear relationship that was fit to data acquired during the first 10 min before PKA stimulation. The adjusted data are shown in $B$ and $C$.

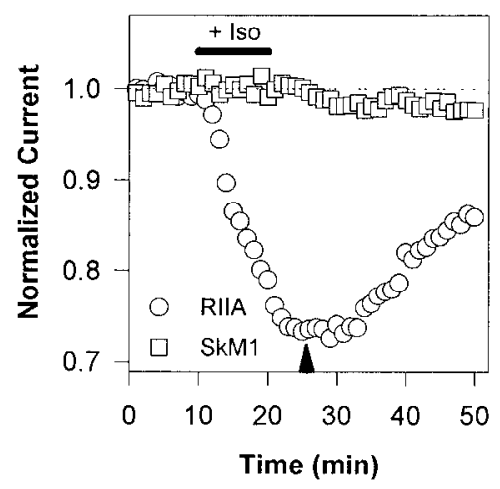

C

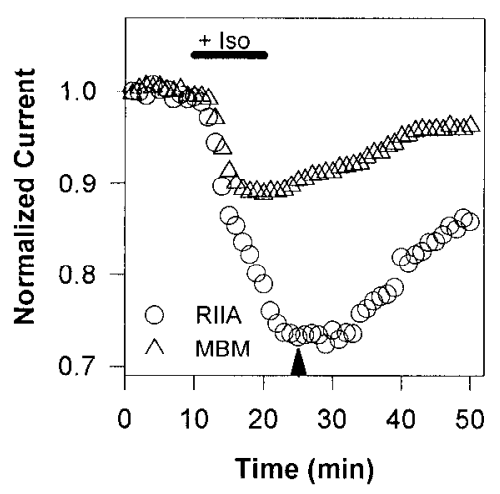

B

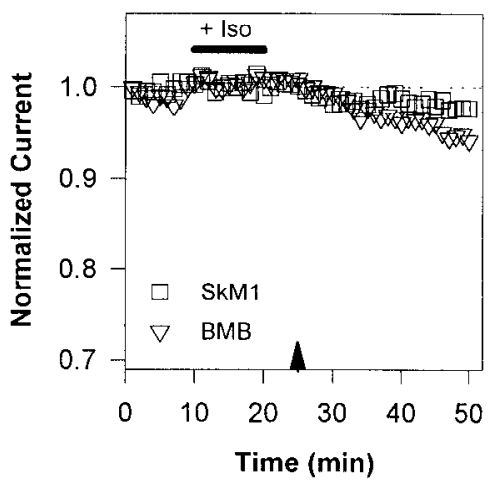

D

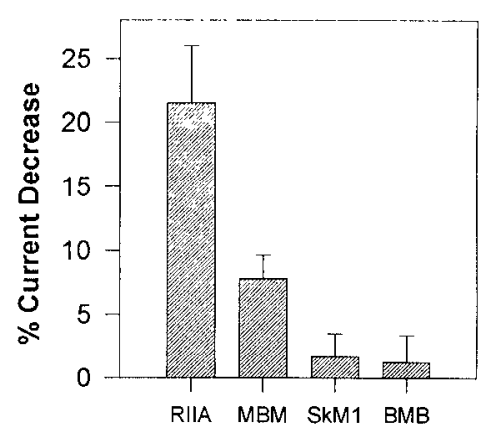

encoding the $\beta$-adrenergic receptor ( $\beta$-AR), which couples through $\mathrm{G}_{\mathrm{s}}$ to activate adenylyl cyclase and elevate cytosolic cAMP levels, inducing PKA activity. When PKA was induced by perfusion with the $\beta$-AR agonist isoproterenol, the current magnitude of the brain channel declined within $15 \mathrm{~min}$, which was followed by a gradual return toward the basal level of current (Fig. 2A, circles). The average reduction in current amplitude 15 min after PKA induction was $21 \pm 5 \%$ (Fig. $2 D$ ). A comparable decrease also was observed when cAMP levels were increased by perfusion of the oocytes with $25 \mu \mathrm{M}$ forskolin, $10 \mu \mathrm{M}$ isobutylmethylxanthine, $10 \mu \mathrm{M}$ dibutyryl-cAMP, and $10 \mu \mathrm{M}$ chlorophenylthio-cAMP (data not shown), demonstrating that the decrease does not result from a secondary effect of the $\beta$-AR. The decrease is similar to the results obtained by $\mathrm{Li}$ et al. (1992) and Gerson et al. (1992). The current magnitude of the muscle channel, however, was unchanged by induction of PKA activity (Fig. $2 A$, squares, and Fig. $2 D$ ). These results demonstrate that the decrease in current resulting from PKA induction is not a gencral property of sodium channels, but is specific to the brain channel.

To determine whether the different responses of the brain and muscle channels after PKA activation are the result of sequence differences in the linkers between domains I and II, chimeric channels were constructed by exchanging the I-II linkers of the brain and muscle sodium channels (Fig. $1 A$ ). The brain-musclebrain (BMB) chimera, which was identical to the brain channel except for the muscle I-II linker, did not respond to PKA induc- tion (Fig. $2 B$, inverted triangles). The lack of response for the BMB chimera was similar to that observed for the muscle channel (Fig. $2 B, D)$. This result demonstrates that the I-II linker region of the brain channel plays an essential role in the PKA-mediated reduction of current magnitude. In contrast, the muscle-brain-muscle (MBM) chimeric channel, which is identical to the muscle channel except for the brain I-II linker, demonstrated a reduction in current within 10 min after PKA induction, followed by a return toward the baseline current (Fig. 2C, triangles). This result was similar to that observed for the brain channel and indicates that the brain I-II linker also can function as a regulatory domain when in the context of the muscle channel. The decrease in current for the BMB chimera was smaller than that observed for the brain channel, with a decrease of $7 \pm 2 \%$ for the $\mathrm{BMB}$ chimera compared with $21 \pm 5 \%$ for the brain channel (Fig. $2 D$ ). Therefore, the brain channel linker does not function as cfficiently for modulation in the skeletal muscle channel background as it does in the brain channel background. Although current levels did gradually decrease over time for both the muscle and BMB channels, most likely those decreases were attributable to channel rundown. In no case did PKA induction cause a decrease in the current magnitude for these channels followed by a return back to the original current level, as always was seen for the brain and MBM channels. Complete recovery from down modulation for the brain and MBM channels usually was observed within $80 \mathrm{~min}$ and most likely was attributable to protein dephosphorylation. 


\section{Elimination of the I-II linker PKA sites does not affect the electrophysiological properties of the channel}

The results with the chimeric channels indicated that the differences in response to PKA activation were the result of sequence differences in the I-II linker. To test specifically whether the PKA sites in the I-II linker of the brain channel are involved in the response to PKA activation, the five sites were eliminated by either deletion or site-directed mutagenesis (Fig. 1B). To remove all of the sites, a single deletion of 139 amino acid residues in the central portion of the linker was constructed ( $\triangle \mathrm{PKA})$. Alternatively, to prevent phosphorylation at all of the sites, site-directed mutagenesis was used to collectively replace all of the serine residues at the five PKA sites. The serines were replaced with alanines, a conservative substitution that should not have a significant impact on protein structure, to generate the PKA composite alanine mutant (PKACOMP-A). At the two sites where more than one serine residue was present (sites 1 and 5), all of the serines were replaced with alanines to prevent phosphorylation at a secondary serine, which might occur if only the consensus serine were replaced with alanine. In an attempt to mimic the negative charges resulting from phosphorylation at the PKA sites, the serine residues at the five sites were substituted collectively with aspartates, such that all of the sites would be constitutively negatively charged. This channel was called the PKA composite aspartate mutant (PKACOMP-D).

The electrophysiological properties of the deletion mutant and the site-specific mutants were characterized by two-clectrode voltage-clamp analysis. Representative current traces appear similar with respect to the time course of fast inactivation (Fig. $3 A$ ). All of the mutants were capable of interacting with the $\beta 1$ accessory subunit in a similar manner as the wild-type channel (Isom et al., 1992; Patton et al., 1994), as indicated by an accelerated time course of fast inactivation (data not shown). Recovery from fast inactivation was unaffected, and full recovery was observed for all of the channels within $2 \mathrm{sec}$ (Fig. $3 B$ ). The voltage dependence of conductance and fast inactivation were determined, and the results are shown in Figure $3 C, D$. Conductance and inactivation data were fit with two-state Boltzmann equations (smooth curves in Figs. $3 C, D)$. Membrane depolarizations required for halfmaximal activation $\left(V_{1 / 2}\right)$ of all of the mutant and wild-type channels were $-13.4 \pm 0.6 \mathrm{mV}$, and the slope factors $(z)$ were 4.1 \pm 0.1 . For inactivation, $V_{1 / 2}$ values for all of the mutant and wild-type channels were $-48.7 \pm 0.9 \mathrm{mV}$, and the slope factors $(a)$ were $7.3 \pm 0.3 \mathrm{mV}$. The finding that all of these properties of the mutants were virtually identical to those of the wild-type channel indicates that the entire central region of the I-II linker in general, which was deleted in $\triangle \mathrm{PKA}$, and the PKA sites specifically, do not contribute significantly to the process of fast inactivation or to the voltage dependence of activation or inactivation.

\section{The sodium channel I-II linker PKA sites are phosphorylated by endogenous oocyte protein kinase}

Although it has been shown previously that the PKA sites in the I-II linker of the brain channel are phosphorylated by PKA in neurons (Costa et al., 1982; Rossie et al., 1987; Rossie and Catterall, 1989), it was possible that these residues were not being phosphorylated in the oocyte. To determine whether the PKA sites in the I-II linker are substrates for phosphorylation by endogenous oocyte protein kinases, the wild-type and mutant channels were expressed in oocytes, and channel proteins were analyzed biochemically. To measure the level of phosphorylation of the mutants in comparison to the wild-type channel, the pro- teins were radiolabeled in vivo with $\left[\gamma_{-3}{ }^{32} \mathrm{P}\right] \mathrm{ATP}$, immunoprecipitated, analyzed by SDS polyacrylamide gel electrophoresis, and autoradiographed. The resulting profile of ${ }^{32} \mathrm{P}$-labeled proteins is shown in Figure $4 A$, lanes 7-10. In parallel sets of oocytes, the channel proteins were radiolabeled with $\left[{ }^{35} \mathrm{~S}\right]$ methionine to quantify the total amount of protein synthesized (Fig. $4 \mathrm{~A}$, lanes 2-5). The majority of sodium channel protein migrated as a single band at $-260 \mathrm{kDa}$ (indicated by an asterisk), although some protein remained at the interface between the stacking and running gels (upper band). No bands were visible in the control lanes ( 2 and 7 ), which contain protein immunoprecipitated from oocytes that were not injected with sodium channel RNA. Variations in the total amount of protein synthesized were controlled by normalizing the ${ }^{32} \mathrm{P}$ signal to the ${ }^{35} \mathrm{~S}$ signal (Fig. $4 B$ ). It was important to normalize the ${ }^{32} \mathrm{P}$ signal, because the steady-state levels of $\triangle \mathrm{PKA}$ and PKACOMP-A mutant proteins were 3.8 times and 2.4 times higher than the level of wild-type protein, as determined by ${ }^{35} \mathrm{~S}$ label (compare the intensity of the bands indicated by an asterisk in lanes 3 and 4 to that in lane 5). The greater amount of $\triangle P K A$ protein isolated may reflect either a faster rate of synthesis or a decreased rate of $\triangle \mathrm{PKA}$ protein turnover, either of which would lead to a higher steady-state level of protein. The wild-type channel was phosphorylated at a level 5 to 10 times greater than that of the deletion and composite PKA site mutants (Fig. 4B). Because this experiment measured the basal level of phosphorylation in the oocytes, this result defines the minimum difference in phosphorylation level between the wild-type and mutant channels. After PKA induction, that difference would be even more pronounced. These results demonstrate that the PKA sites in the I-II linker indeed are phosphorylated in the oocyte. Residual phosphorylation of the mutant channels can be attributcd to phosphorylation at other sites in the channel protein by a variety of protein kinases.

\section{Sodium currents expressed from the PKA site mutants are not decreased by PKA}

The PKA site mutants were coexpressed with the $\beta$-AR in Xenopus oocytes to determine whether they could be modulated by PKA activation. In this experiment, the average reduction in current for the wild-type channel was $11 \%$ (Fig. $5 A, B$ ), compared with the $22 \%$ reduction observed in the experiment shown in Figure 2. This difference results from variability in the oocytes from different frogs. All three of the mutants ( $\triangle \mathrm{PKA}$, PKACOMP-A, and PKACOMP-D) did not demonstrate reductions in current amplitude after induction of PKA (Fig. 5A,B). Instead, they all displayed $\sim 30 \%$ increases in current magnitude. This increase also was observed when cAMP levels were increased by perfusion of the oocytes with $25 \mu \mathrm{m}$ forskolin, $10 \mu \mathrm{M}$ isobutylmethylxanthine, $10 \mu \mathrm{M}$ dibutyryl-cAMP, and $10 \mu \mathrm{M}$ chlorophenylthio-cAMP (data not shown), demonstrating that the increase does not result from a secondary effect of the $\beta$-AR. The time courses of the current increases for the mutant channels paralleled the time course of current decrease for the wild-type channel, and in all cases the current milagniludes returned to the original level within $80 \mathrm{~min}$. These results indicate that the reduction of current magnitude by PKA requires at least a subset of the five PKA sites in the I-II linker.

\section{Negative charges at the I-II linker PKA sites decrease sodium current}

To examine the importance of phosphorylation at the PKA sites in the I-II linker for the establishment of basal current levels in 


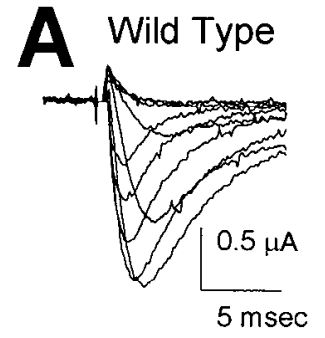

B

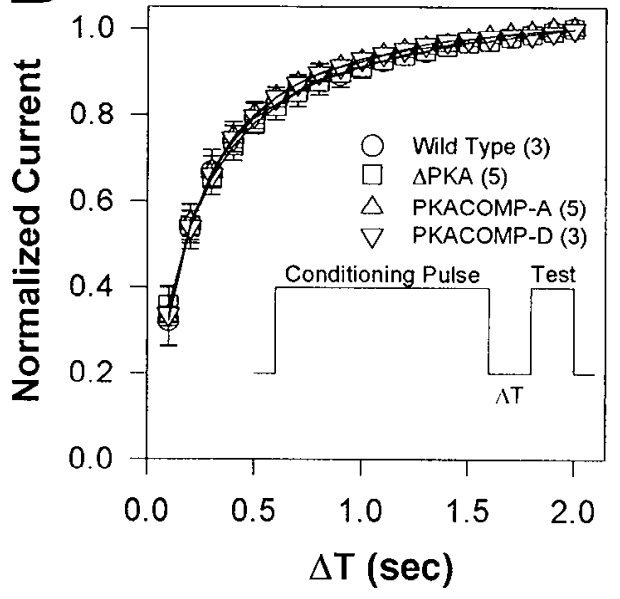

D

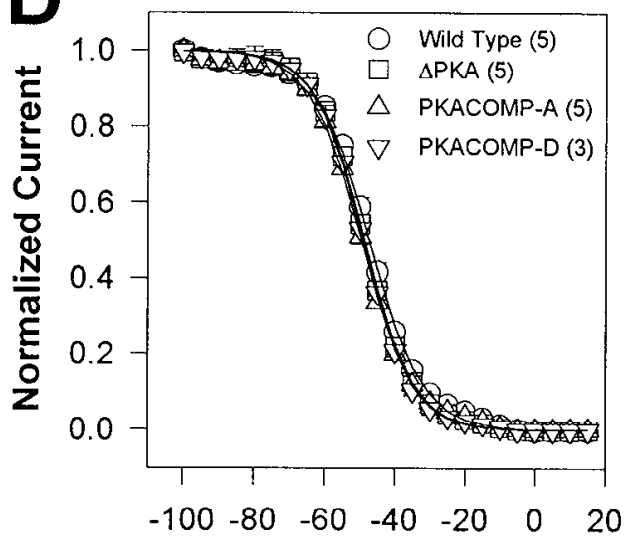

PKACOMP-A PKACOMP-D
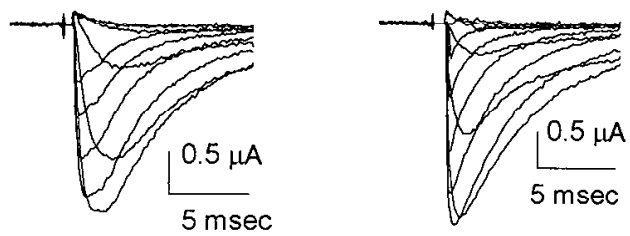

C

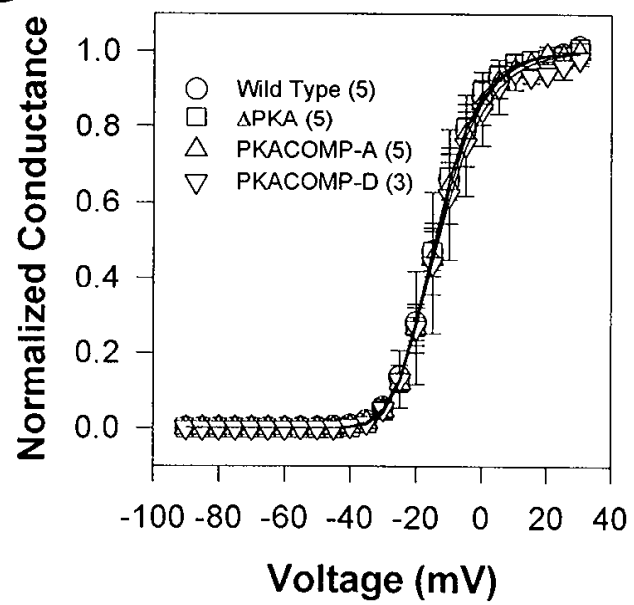

Voltage $(\mathrm{mV})$

Figure 3. Elimination of the I-II linker PKA sites does not affect the electrophysiological properties of the channel. $A$, Representative current traces from oocytes injected with RNA cncoding the wild-type brain IIA sodium channel (Wild Type), the mutant channel with the PKA sites eliminated by deletion $(\triangle P K A)$, or the mutant channels in which the serine residues were replaced with alanines $(P K A C O M P-A)$ or aspartates $(P K A C O M P-D)$. Currents were elicited by step depolarizations from -90 to $+50 \mathrm{mV}$ in $5 \mathrm{mV}$ increments from a holding potential of $-100 \mathrm{mV}$. The traces shown are for depolarizations from -35 to $+10 \mathrm{mV}$. Resistive and capacitive currents were eliminated by subtraction of currents elicited by identical pulse protocols in the presence of $400 \mathrm{~nm}$ tetrodotoxin. $B$, The time course of recovery from inactivation is shown for currents expressed by each of the four sodium channels described in $A$. Oocytes were held at $-100 \mathrm{mV}$ and depolarized to $-5 \mathrm{mV}$ for $200 \mathrm{msec}$ (inactivating pulse), followed by a variable recovery interval at $-100 \mathrm{mV}$ and a $20 \mathrm{msec}$ test pulse to $-5 \mathrm{mV}$. The peak current amplitude during the test pulse was normalized to the maximal current that was observed after full recovery from inactivation. The average value for the normalized current is plotted versus the recovery time $(\Delta T)$ between pulses for the number of oocytes shown in parentheses after the channel names on the figurc. The enor bars indicate the sample SD. $C$, Normalized conductance versus voltage is shown for currents expressed from each of the four sodium channels described in $A$. Currents were elicited by membrane depolarization from $-90 \mathrm{mV}$ to $+35 \mathrm{mV}$ in $5 \mathrm{mV}$ increments from a holding potential of $-100 \mathrm{mV}$. Peak current amplitudes were converted to conductance values as described in Materials and Methods. The values shown represent the average for the number of oocytes shown in parentheses after the channel names on the figure. The error bars indicate the sample SDs, and the smooth curves represent fits of the data to a two-state Boltzmann distribution, as described in Materials and Methods. $D$, The voltage dependence of inactivation is shown for currents expressed from each of the four sodium channels described in $A$. Oocytes were held at $-100 \mathrm{mV}$ and depolarized with $200 \mathrm{msec}$ conditioning pulses ranging from -100 to $+15 \mathrm{mV}$ in $5 \mathrm{mV}$ increments, followed by a test pulse to $-5 \mathrm{mV}$. The peak current during the test pulse was normalized to the peak current in the absence of a conditioning pulse and plotted as a function of conditioning pulse potential. The values shown represent the average for the number of oocytes shown in parentheses after the channel names on the figure. The error bars indicate the sample SDs, and the smooth curves represent fits of the data to a two-state Boltzmann distribution, as described in Materials and Methods. 

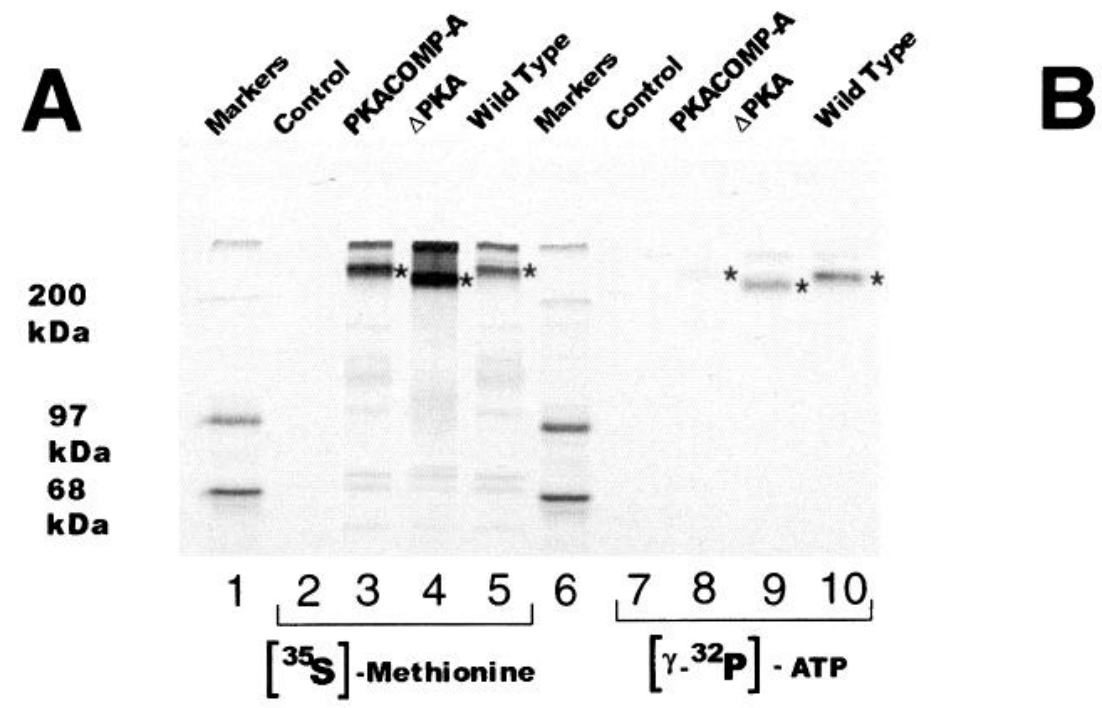

Figure 4. The sodium channel I-II linker PKA sites are phosphorylated by oocyte protein kinases. $A$, Oocytes were injected with RNA encoding wild-type or mutant sodium channels, and the proteins were labeled with either $\left[{ }^{35}\right.$ S $]$ methionine or $\left[\gamma^{32} \mathrm{P}\right] \mathrm{ATP}$, as described in Materials and Methods. Sodium channel proteins were extracted from oocyte membrane fractions, immunoprecipitated, and electrophoresed in an SDS-polyacrylamide gel, followed by autoradiography, as described in Materials and Methods. The samples are as follows: lanes 1,6-molecular size markers; lanes 2, 7-control oocytes that were not injected; lanes 3, 8-oocytes expressing the PKACOMP-A mutant (serine residues replaced by alanines); lanes 4, 9-oocytes expressing the $\triangle$ PKA mutant (PKA site deletion mutant); lanes 5, 10-oocytes expressing the wild-type sodium channel. The proteins in lanes 2-5 were labeled with $\left[{ }^{35} \mathrm{~S}\right]$ methionine, and the proteins in lanes $7-10$ were labeled with $\left[\gamma_{-}{ }^{32} \mathrm{P}\right] \mathrm{ATP}$. The asterisks indicate the positions of the sodium channel bands. B, The autoradiograph in $A$ was scanned, and the intensities of ${ }^{35} \mathrm{~S}$ and ${ }^{32} \mathrm{P}$ in the bands representing sodium channel protein (indicated by an asterisk) were quantified. The ${ }^{32} \mathrm{P}$ signals were normalized to the ${ }^{35} \mathrm{~S}$ signals to control for the variation in the total amount of sodium channel protein immunoprecipitated from each of the samples. The normalized ${ }^{32} \mathrm{P}$ signal is shown for the wild-type sodium channel (Wild Type), the PKA site deletion mutant $(\triangle P K A)$, and the mutant in which serine residues are replaced by alanines (PKACOMP-A).

oocytes, the wild-type and mutant channels were compared without induction of PKA activity. Oocytes were injected with the same amount of RNA for each of the mutants, and the level of sodium current expressed after reaching steady-state levels was normalized to the amount of channel protein isolated from oocyte membranes. To quantify full-length $\sim 6.8 \mathrm{~kb}$ RNA transcripts, radiolabeled RNA was analyzed by gel electrophoresis, autoradiography, and densitometry (Fig. 6A). To measure the amount of channel protein translated and inserted into oocyte membranes, sodium channel protein was immunoprecipitated from oocyte membrane fractions. Bands corresponding to a molecular weight of $\sim 260 \mathrm{kDa}$ were measured by densitometry (Fig. 6B, arrow). Before homogenizing the oocytes for immunoprecipitation, whole-cell sodium current amplitudes were measured in representative oocytes by two-electrode voltage clamping. Peak current amplitudes were normalized to the amount of protein isolated. Normalized current values are expressed relative to the wild-type channel (Fig. 6C). The $\triangle \mathrm{PKA}$ and PKACOMP-A mutants expressed current magnitudes comparable to that observed for the wild-type channel (Fig. 6C). This result suggests that basal levels of phosphorylation in the oocyte are relatively low, so that the PKA sites on the wild-type channel are not phosphorylated sufficiently to have a dramatic effect. When the negative charge of aspartate was positioned at all five of the PKA sites to mimic phosphorylation, the sodium current amplitude was reduced significantly to $59 \pm 8 \%$ the level of the wild-type channel (Fig. $6 C$ ). This result suggests that the negative charges added to the PKA sites by phosphorylation are responsible for decreases in current amplitude and that the negative charges of the aspartate residues can mimic phosphorylation at those sites.

\section{DISCUSSION}

The I-I linker is a critical determinant for modulation of the brain sodium channel by PKA

We have shown that the rat brain IIA sodium channel can be modulated by PKA to result in decreased current amplitudes, but that the rat skeletal muscle channel is not affected by PKA induction. We demonstrated also that PKA-mediated reduction of brain sodium channel current amplitude requires phosphorylation of the PKA consensus sites located in the linker region between domains I and II of the $\alpha$ subunit. We showed initially that the brain I-II linker is a necessary determinant for modulation by PKA. This was indicated by the BMB chimera, which has the muscle I-II linker in a brain channel background, and completely failed to respond to PKA activation. Conversely, replacement of the muscle sodium channel I-II linker with the brain channel I-II linker (MBM chimera) was sufficient to cause the muscle channel to be modulated by PKA, similar to the brain sodium channel. Because the magnitude of current decrease observed for the MBM chimera was significantly less than that observed for the brain channel, it is apparent that the brain I-II linker does not function as efficiently in the context of the muscle channel, indicating that other regions of the sodium channel molecule are important to bring about full modulation. The finding that the brain channels respond to PKA induction and the muscle channels does not suggest that there may be important physiological differences in the regulation of electrical excitability in the tissues in which these channels are expressed.

PKA modulation of the sodium channel involves phosphorylation at the I-II linker PKA consensus sites

We further demonstrated that phosphorylation of the I-II linker PKA sites is required for PKA mediated reduction of sodium 

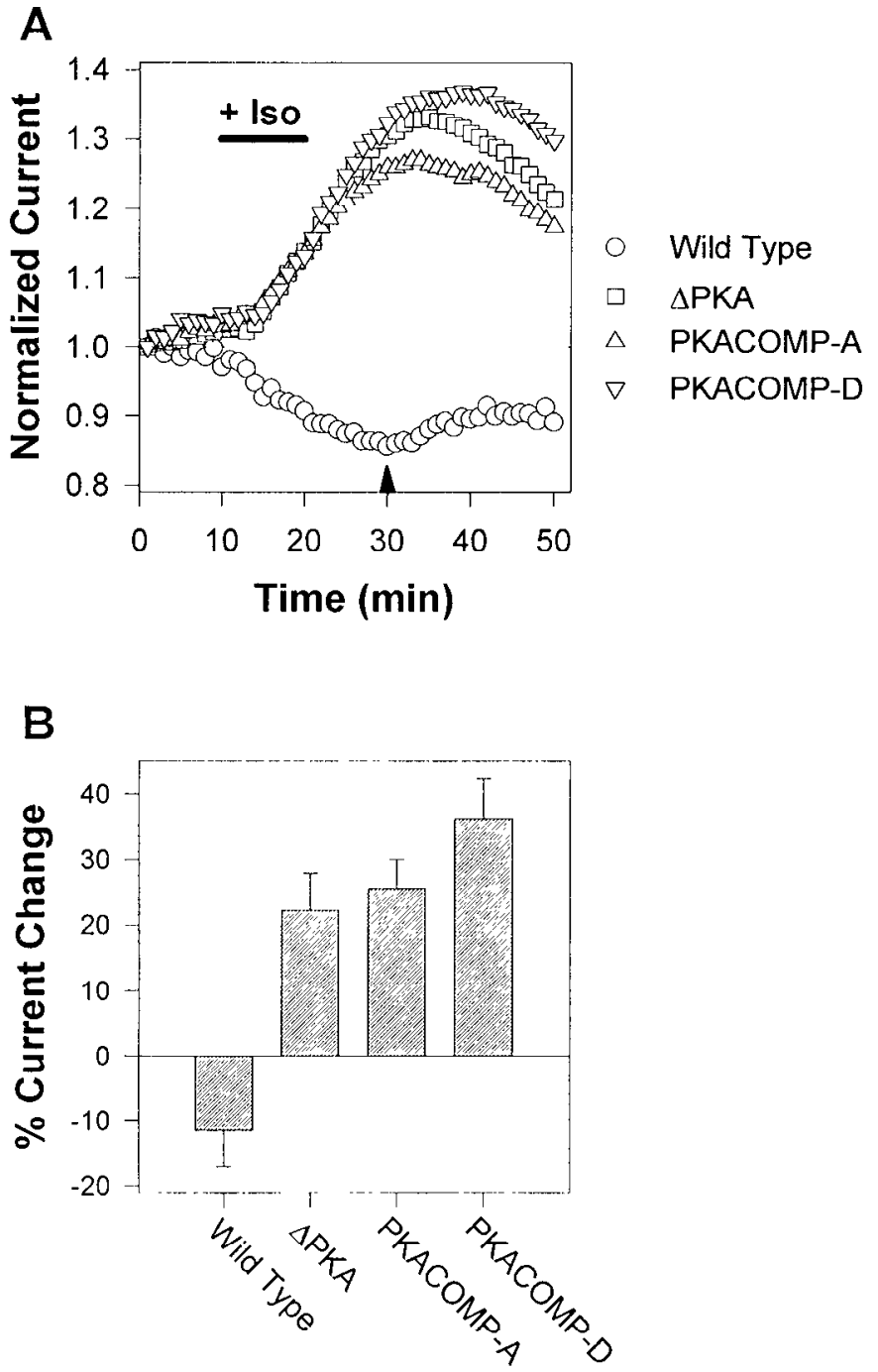

Figure 5. Reduction of sodium current amplitude by PKA involves phosphorylation at the I-II linker PKA consensus sites. $A$, Normalized peak current amplitudes are shown for representative oocytes injected with RNA encoding the $\beta$-AR and either the brain IIA channel (RIIA; circles), the PKA site deletion mutant ( $\triangle P K A$; squares), the composite mutant in which the serines are replaced by alanines (PKACOMP-A; triangles), or the composite mutant in which the serines are replaced by aspartates (PKACOMP-D; inverted triangles). Currents were elicited by step depolarizations from a holding potential of -100 to $-10 \mathrm{mV}$ at 1 min intervals, and the peak current amplitudes were normalized to the peak current amplitude during the first depolarization. PKA was induced by perfusion with Iso $(+I s o)$ for 10 min during the time indicated by the bar. $B$, The percent of current change 20 min after PKA induction (indicated by the arrowhead on the time axis in $A$ ) is shown for the wild-type and mutant sodium channels. The values shown are the averages for three oocytes (RIIA), four oocytes $(\triangle P K A)$, six oocytes $(P K A C O M P-A)$, and three oocytes $(P K A C O M P-D)$, and the error bars indicate the sample SDs.

current magnitude. First, we showed that the sites are substrates for phosphorylation by PKA in the oocyte, by demonstrating a 5to 10 -fold greater ${ }^{32} \mathrm{P}$ incorporation into the wild-type channel protein compared with the mutant channel proteins. Because these sites in the I-II linker serve as substrates for PKA in oocytes with basal levels of PKA activity, it would be expected that the same sites would be phosphorylated to a greater extent after PKA stimulation. Second, when the five sites were deleted or phosphorylation at the sites was prevented, sodium current amplitude was no longer diminished by PKA activation. Other functional properties of the channel, including fast inactivation, recovery from inactivation, and the voltage-dependence of conductance and inactivation, were not affected by mutations at the PKA sites. These results are consistent with previous observations that these channel properties are not altered by PKA phosphorylation (Gershon et al., 1992; Li et al., 1992; Smith and Goldin, 1992; Li et al., 1993). The absence of any significant alterations in these elcctrophysiological properties supports the assumption that replacement of the serines with either alanines or aspartates does not alter the structure of the channel protein significantly. In fact, even deletion of 139 amino acids from the linker ( $\triangle P K A)$ apparently has no effect on these electrophysiological properties of the channel. The finding that the wild-type channel is downmodulated by PKA activation in oocytes indicates that the PKC site at $\mathrm{S} 1506$ in the III-IV linker normally must be phosphorylated in oocytes, because modulation by PKA does not occur unless there is a negative charge at that site (Li ct al., 1993).

\section{Negative charge at the I-II linker PKA sites is sufficient to modulate the channel}

Based on our results, it seems likely that the molecular mechanism by which the channel is modulated by phosphorylation involves charge interactions between the negative charge of the phosphate groups at the PKA sites and other regions of the channel. Xenopus oocytes have been measured to have an internal pH of 7.5 (Sasaki et al., 1992). At that $\mathrm{pH}$, the phosphate groups on phosphoserine would have a charge of -1 , based on their $\mathrm{p} K_{\mathrm{i}}$ of 6.1 (Hoffmann et al., 1994). Similarly, aspartate residues, which have a $\mathrm{p} K_{\mathrm{a}}$ of 4.5 , would have a charge of -1 . Therefore, an aspartate residue is very similar to phosphoserine, at least with respect to charge, and replacement of serines with aspartates has been used successfully to mimic phosphorylation (Li et al., 1993; Rich et al., 1993). When the negative charge of aspartate was positioned at each of the five PKA sites in the PKACOMP-D mutant, the sodium current amplitude was reduced, similar to the result observed when the sites were phosphorylated by PKA activation. The mechanism by which the negative charges cause a decrease in current is unknown. It is unlikely that the reduction of current amplitude was caused by disruption of the channel's structure, because the electrophysiological properties of the PKACOMP-D mutant were similar to those of the wild-type channel. In addition, we have confirmed that the PKACOMP-D mutant is translated and inserted into the membrane as efficiently as the wild-type channel by comparing the amount of sodium channel protein immunoprecipitated from oocytes. The most likely explanation is that the negatively charged phosphates interact with other regions of the channel molecule through salt bridges or by electrostatic effects, resulting in a decrease in either the single channel conductance or the probability of opening.

\section{Mutants with PKA sites eliminated respond to PKA induction with current magnitude increases}

Elimination of the brain sodium channel I-II linker PKA sites resulted in mutants that responded to PKA induction with increases in sodium current magnitude, rather than the decrease observed for the wild-type channel. The mechanism leading to the increase is completely independent of the PKA sites in the I-II linker, as the effect is observed for mutants in which all of the sites have been eliminated (PKACOMP-A, PKACOMP-D, and $\triangle \mathrm{PKA})$. It is likely that this increase in sodium current normally is not seen, because it is masked by the decrease resulting from 

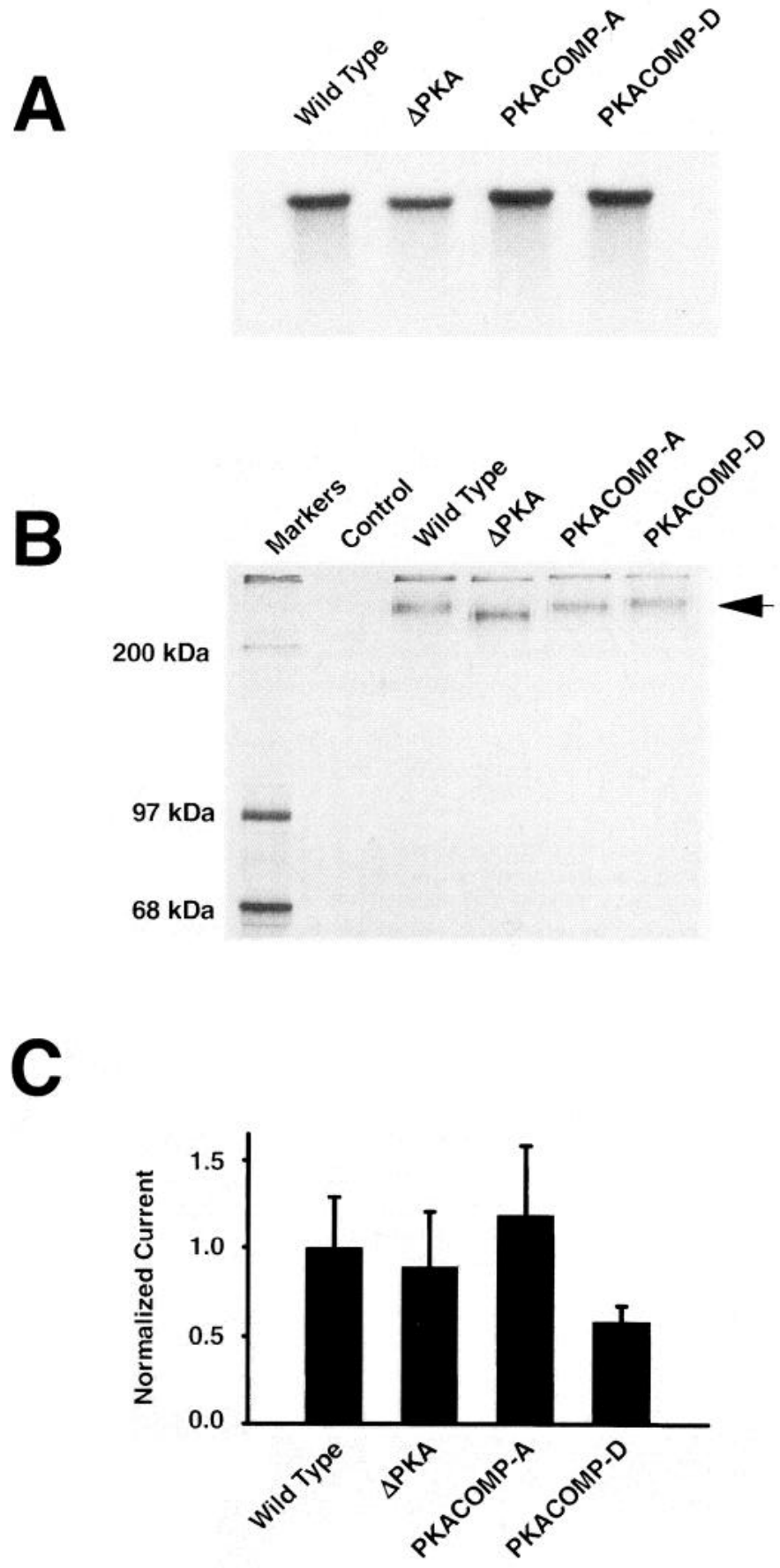

Figure 6. A negative charge at the I-II linker PKA sites is sufficient to decrease sodium currents. A, RNA was transcribed in vitro for the wildtype and mutant sodium channels, using $\left[\alpha-{ }^{32} \mathrm{P}\right] \mathrm{CTP}$ to label the RNA, and samples of each were treated with glyoxal and electrophoresed on a $1 \%$ agarose gel. The gel was exposed to $\mathrm{x}$-ray film, and the resulting autoradiograph is shown. The autoradiograph was scanned, and the intensity of the band indicating full-length sodium channel RNA was quantified. $B$, Sodium channel protein was immunoprecipitated from oocytes. Equivalent amounts of RNA $(25 \mathrm{ng})$ and $\left[{ }^{35} \mathrm{~S}\right]$ methionine $(250 \mathrm{nCi})$ were injected into oocytes and incubated at $20^{\circ} \mathrm{C}$ for $40 \mathrm{hr}$ for the wild-type and mutant channels. Control oocytes were injected with $\left[{ }^{35} \mathrm{~S}\right]$ methionine alone. Sodium channel proteins were extracted from oocyte membrane fractions, immunoprecipitated, and electrophoresed on an SDSpolyacrylamide gel, followed by autoradiography, as described in Materials and Methods. The protein bands with $M_{\mathrm{r}} \approx 260 \mathrm{kDa}$ (arrow) were scanned and quantified. $C$, Current amplitudes were measured in representative oocytes before extraction of protein and are normalized to the amount of protein that was isolated subsequently by immunoprecipitation. phosphorylation at the PKA sites in the I-II linker. The mechanism leading to the increase in current is not understood at this time. The increase was not observed for the skeletal muscle sodium channel, indicating that it is specific for the brain channel. Similarly, the BMB chimera did not display an increase in current magnitude after PKA induction in this study. These results suggest that the increase in current may be associated with the I-II linker of the brain channel, involving amino acid sequences upstream or downstream of the region deleted in the $\triangle$ PKA mutant. Schreibmayer et al. (1994) have reported a similar PKA-mediated increase in sodium current expressed from the rat cardiac sodium channel in Xenopus oocytes.

We reported previously that PKA phosphorylation in oocytes could enhance sodium current levels expressed from the brain IIA sodium channel, and that this increase was prevented by inhibiting PKA activity with protein kinase inhibitor (Smith and Goldin, 1992). The difference between our previous studies, in which an increase in sodium currents was observed, and our current study, in which a decrease is observed, is the level of expression of the $\beta$-AR. The previous studies were performed with the $\beta$-AR expressed at a level 100 -fold higher than was used in the current study. At that higher level of expression, there is an endogenous stimulation of PKA activity in the absence of isoproterenol perfusion (Uezono et al., 1993), which most likely results in phosphorylation of the PKA sites in the I-II linker of the sodium channel, reducing the amplitude of the current. Stimulation with isoproterenol then would result in an even higher level of PKA activity, causing the increase in sodium currents by a mechanism completely independent of phosphorylation at the PKA sites in the I-II linker. That increase is the only effect of PKA stimulation when the five PKA sites in the I-II linker have been eliminated.

\section{The next step: understanding the individual roles of each of the PKA sites}

The obvious next step is to examine how each of the PKA sites in the I-II linker participate in PKA modulation of the sodium channel. Murphy et al. (1993) demonstrated that four of the PKA sites in the I-II linker (S573, S610, S623, and S686/S687) are phosphorylated to a detectable level in vivo using biochemical techniques. Hebert et al. (1994) implicated the PKA site at position $\mathrm{S} 686 / \mathrm{S} 687$ as being involved in sodium current reduction. However, prevention of phosphorylation by replacing the serines at S686 and S687 with alanines does not eliminate the decrease in current after stimulation of PKA activity (Smith and Goldin, unpublished results). Therefore, at least part of the decreased current amplitudes after PKA induction results from the presence of a negative charge at some other site in the I-II linker. It is quite possible that multiple sites are involved in the decrease of sodium

In ND-96 bath solution, the current levels in these oocytes was $\sim 50 \mu \mathrm{A}$. To maintain voltage control using a two-electrode voltage clamp with oocytes expressing such high levels of sodium current, sodium in the bath was reduced by substituting with choline. Peak sodium current amplitudes were measured by depolarizing to $-20 \mathrm{mV}$ from a holding potential of $-100 \mathrm{mV}$. The average peak current amplitudes from individual oocytes were normalized to the average peak current amplitude for the wild-type channel. The average normalized current measured from 15 oocytes for each of the mutant and wild-type channels is shown, and the error bars indicate one sample SD. The normalized current amplitude for PKACOMP-D was significantly different from that of the wild-type, $\triangle$ PKA, and PKACOMP-A mutants $(p<0.05)$, as determined by using a one-way ANOVA. The normalized current amplitudes for the wild-type, $\triangle \mathrm{PKA}$, and PKACOMP-A mutants were not significantly different from each other. 
channel currents by PKA phosphorylation, which would imply that sodium current amplitudes could be variably modulated depending on the level of PKA and phosphatase activity in the cell. It has become increasingly clear that regulation of the sodium channel in vivo by PKA phosphorylation involves a complex assemblage of protein kinases and phosphatases that appear to precisely modulate sodium current amplitudes in electrically excitable cells.

\section{REFERENCES}

Auld VJ, Goldin AL, Krafte DS, Catterall WA, Lester HA, Davidson N, Dunn RJ (1990) A neutral amino acid change in segment IIS4 dramatically alters the gating properties of the voltage-dependent sodium channel. Proc Natl Acad Sci USA 87:323-327.

Chen T-C, Law B, Kondratyuk T, Rossie S (1995) Identification of soluble protein phosphatases that dephosphorylate voltage-sensitive sodium channels in rat brain. J Biol Chem 270:7750-7756.

Costa MR, Casnellie JE, Catterall WA (1982) Selective phosphorylation of the $\alpha$ subunit of the sodium channel by cAMP-dependent protein kinase. J Biol Chem 257:7918-7921.

Dascal N, Lotan I (1991) Activation of protein kinase C alters voltage dependence of a $\mathrm{Na}^{+}$channel. Neuron 6:165-175.

Gershon E, Weigl L, Lotan I, Schrcibmayer W, Dascal N (1992) Protcin kinase A reduces voltage-dependent $\mathrm{Nal}^{\prime}$ current in Xenopus oocytes. J Neurosci 12:3743-3752.

Goldin AL (1991) Expression of ion channcls by injection of $m$ RNA into Xenopus oocytes. Methods Cell Biol 36:487-509.

Hebert TE, Monette R, Stone JC, Drapeau P, Dunn RJ (1994) Insertion mutations of the RIIA $\mathrm{Na}^{+}$channel reveal novel features of voltage gating and protein kinase A modulation. Pfligers Arch 427:500-509.

Hoffmann R, Reichert I, Wachs WO, Zeppezauer M, Kalbitzer HR (1994) ${ }^{1} \mathrm{H}$ and ${ }^{31} \mathrm{P}$ NMR spectroscopy of phosphorylated model peptides. Int J Pept Protein Res 44:193-198.

Hopp TP, Prickett KS, Price VL, Libby RT, March CJ, Cerretti DP, Urdal DL, Conlon PJ (1988) A short polypeptide marker sequence useful for recombinant protein identification and purification. Biotechnology $6: 1204-1210$.

Isom LL, DcJongh KS, Patton DE, Rcber BFX, Offord $\mathbf{J}$, Charbonneau H, Walsh K, Goldin AL, Catterall WA (1992) Primary structure and functional expression of the $\beta_{1}$ subunit of the rat brain sodium channel. Science 256:839-842.

Kemp BE, Pearson RB (1990) Protein kinase recognition sequence motifs. Trends Biochem Sci 15:342-346.

Kontis KJ, Goldin AL (1993) Site-directed mutagenesis of the putative pore region of the rat IIA sodium channel. Mol Pharmacol 43:635-644.

Kunkel TA (1985) Rapid and efficient site-specific mutagenesis without phenotypic selection. Proc Natl Acad Sci USA 82:488-492.

Li M, West JW, Lai Y, Scheuer T, Catterall WA (1992) Functional modulation of brain sodium channels by cAMP-dependent phosphorylation. Neuron 8:1151-1159.
Li M, West JW, Numann R, Murphy BJ, Scheuer T, Catterall WA (1993) Convergent regulation of sodium channels by protein kinase $\mathrm{C}$ and cAMP-dependent protein kinase. Science 261:1439-1442.

Murphy BJ, Rossie S, DeJongh KS, Catterall WA (1993) Identification of the sites of selective phosphorylation and dephosphorylation of the rat brain $\mathrm{Na}^{+}$channel $\alpha$ subunit by cAMP-dependent protein kinase and phosphoprotein phosphatases. J Biol Chem 268:27355-27362.

Numann R, Catterall WA, Scheuer T (1991) Functional modulation of brain sodium channels by protein kinase $\mathrm{C}$ phosphorylation. Science 254:115-118.

Patton DE, Goldin AL (1991) A voltage-dependent gating transition induces use-dependent block by tetrodotoxin of rat IIA sodium channels expressed in Xenopus oocytes. Neuron 7:637-647.

Patton DE, Isom LL, Catterall WA, Goldin AL (1994) The adult rat brain $\beta_{1}$ subunit modifies activation and inactivation gating of multiple sodium channel $\alpha$ subunits. J Biol Chem 269:17649-17655.

Rich DP, Berger HA, Cheng SH, Travis SM, Saxena M, Smith AE, Welsh MJ (1993) Regulation of the cystic fibrosis transmembrane conductance regulator $\mathrm{Cl}^{-}$channel by negative charge in the $\mathrm{R}$ domain. $\mathrm{J}$ Biol Chem 268:20259-20267.

Rossic S, Gordon D, Catterall WA (1987) Identification of an intracellular domain of the sodium channel having multiple cAMP-dependent phosphorylation sites. J Biol Chem 262:17530 17535.

Rossic S, Catterall WA (1989) Phosphorylation of the $\alpha$ subunit of rat brain sodium channels by cAMP-dependent protein kinasc at a new site

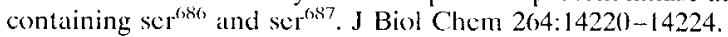

Santacruz-Toloza L, Huang Y, John SA, Papazian DM (1994) Glycosylation of Shaker potassium channel protein in insect cell culture and in Xenopas oocytes. Biochemistry 33:56017-5613.

Sasaki S, Ishibashi K, Nagai T, Marumo F (1992) Regulation mechanisms of intracellular $\mathrm{pH}$ of Xenopus laevis oocyte. Biochim Biophys Acta 1137:45-51.

Schreibmayer W, Dascal N, Lotan I, Wallner M, Weigl L (1991) Molecular mechanism of protein kinase $C$ modulation of sodium channel $\alpha$-subunits expressed in Xenopus oocytes. FEBS Lett 291:341-344.

Schreibmayer W, Frohnwieser B, Dascal N, Platzer D, Spreitzer B, Zechner R, Kallen RG, Lester HA (1994) $\beta$-adrenergic modulation of currents produced by rat cardiac $\mathrm{Na}^{+}$channels expressed in Xenopus laevis oocytes. Receptors Channels 2:339-350.

Smith RD, Goldin AL (1992) Protein kinase A phosphorylation enhances sodium channel currents in Xenopus oocytes. Am J Physiol 236:C660-C666.

Trimmer JS, Cooperman SS, I'omiko SA, Zhou J, Crean SM, Boyle MB, Kallen RG, Sheng Z, Barchi RL, Sigworth FJ, Goodman RH, Agnew WS, Mandel G (1989) Primary structure and functional expression of a mammalian skeletal muscle sodium channel. Neuron 3:33-49.

Uezono Y, Bradley J, Min C, McCarty NA, Quick M, Riordan JR, Chavkin C, Zinn K, Lester HA, Davidson N (1993) Receptors that couple to 2 classes of $G$ proteins increase cAMP and activate CFTR expressed in Xenopus oocytes. Receptors Channels 1:233-241.

White MM, Reisine T (1990) Expression of functional pituitary somatostatin receptors in Xenopus oocytes. Proc Natl Acad Sci USA 87:133-136. 